\title{
Therapeutic options in patients with biochemical recurrence after radical prostatectomy (Review)
}

\author{
OVIDIU GABRIEL BRATU ${ }^{1-3}$, CAMELIA CRISTINA DIACONU ${ }^{1,4}$, DAN LIVIU DOREL MISCHIANU ${ }^{1-3}$, \\ TRAIAN CONSTANTIN ${ }^{1,5}$, ANA MARIA ALEXANDRA STANESCU ${ }^{1}$, SIMONA GABRIELA BUNGAU ${ }^{6}$, \\ FLORENTINA IONITA-RADU $^{7}$ and RADU DRAGOS MARCU ${ }^{1,2}$ \\ ${ }^{1}$ University of Medicine and Pharmacy Carol Davila, 050474 Bucharest; ${ }^{2}$ Urology Department, \\ Emergency University Central Military Hospital, 010825 Bucharest; ${ }^{3}$ Academy of Romanian Scientists, \\ 030167 Bucharest; ${ }^{4}$ Internal Medicine Department, Clinical Emergency Hospital of Bucharest, 014461 Bucharest; \\ ${ }^{5}$ Urology Department, 'Prof. Th. Burghele' Clinical Hospital, 050659 Bucharest; ${ }^{6}$ University of Oradea, \\ Faculty of Medicine and Pharmacy, Department of Pharmacy, 410073 Oradea; ${ }^{7}$ Gastroenterology Department, \\ Emergency University Central Military Hospital, 010825 Bucharest, Romania
}

Received June 12, 2019; Accepted August 7, 2019

DOI: $10.3892 /$ etm.2019.7916

\begin{abstract}
Prostate cancer is the second most common form of cancer in men in Europe. The primary treatment of this type of cancer is radical prostatectomy, which has shown good oncological results. Radical prostatectomy (open, laparoscopic or robotic) has high success and low morbidity rates in patients with localized prostate cancer. The life expectancy is $>10$ years after radical prostatectomy. Studies have shown that $\sim 20 \%-30 \%$ of the patients who have undergone radical prostatectomy can develop biochemical recurrence, which is monitored by using the value of the prostate-specific antigen (PSA). In some cases (patients with high-risk prostate cancer), adjuvant therapy after radical prostatectomy, such as radiotherapy or androgen deprivation therapy, can significantly reduce the risk of biochemical recurrence. The optimal management of recurrent disease remains uncertain. Recent literature was systematically reviewed regarding the management of biochemical recurrence and to compare clinical experience in literature studies.
\end{abstract}

\section{Contents}

1. Introduction

2. The natural history of biochemical recurrence

3. Therapeutical options

Correspondence to: Professor Camelia Cristina Diaconu, University of Medicine and Pharmacy Carol Davila, 8 Eroii Sanitari Street, 050474 Bucharest, Romania

E-mail: drcameliadiaconu@gmail.com

Key words: prostate cancer, radical prostatectomy, biochemical recurrence, prostatic specific antigen, therapeutic options
4. Discussion

5. Conclusions

\section{Introduction}

According to the latest guidelines, prostate cancer (PCa) is the second most commonly diagnosed cancer in men, with an estimated 1.1 million diagnoses worldwide in 2012, accounting for $15 \%$ of all diagnosed cancers (1-9). The two most important tools in raising the suspicion of prostate cancer are the prostate-specific antigen (PSA) value and digital rectal examination, the latter offering information on the prostate's characteristics, such as consistence, dimensions, its relations with the adjacent structures, as well as detecting the presence of a nodule on the prostatic surface or an area with a modified consistence that could raise the suspicion of cancer. The prevalence of prostate cancer in patients under 30 years old is $<5 \%$ and it is increasing by an odds ratio of 1.7 (1.6-1.8) per decade to a prevalence of $59 \%$ (48-71\%) in men aged over 79 years (1).

In the setting of organ-confined disease, PSA is supposed to have undetectable values after radical prostatectomy. Despite primary treatment for localized prostate cancer, it is estimated that $20 \%-30 \%$ of these patients can experience a biochemical recurrence, typically detected by the rise of the serum PSA levels. In patients with confined disease, the PSA value should be undetectable following radical prostatectomy, whereas in patients managed with radiotherapy the PSA value decreases slowly, but it does not reach undetectable values. Current guidelines describe biochemical recurrence following radical prostatectomy as two consecutive increases of the PSA value, that are $>0.2 \mathrm{ng} / \mathrm{ml}$. In terms of biochemical recurrence after radiotherapy, this implies the increase of the PSA value with at least $2 \mathrm{ng} / \mathrm{ml}$ over the nadir value, which represents the lowest PSA value achieved after radiotherapy (10). 
Because biochemical recurrence is known to determine distant metastasis and eventually death related to cancer progression, men with biochemical recurrence should undergo salvage therapy and be carefully monitored.

Many studies have been performed in order to examine the characteristics and management of early and late biochemical recurrence after radical prostatectomy. Beauval et al performed a study on 517 patients who underwent radical prostatectomy, including bilateral pelvic lymph node dissection, for clinical high-risk PCa. The PSA value was $>20 \mathrm{ng} / \mathrm{ml}$, the clinical stage was T2c or more and the biopsy Gleason score was between 8 and 10. The study was performed between 1990 and 2013 in two French clinical centers. Open, laparoscopic or robotic-assisted prostatectomy was performed. Lymph node metastasis was noted in $12.4 \%$ of patients. In only 29 cases adjuvant therapy, such as radiotherapy or androgen deprivation therapy (ADT), was recommended. Biochemical recurrence-free survival was $56.4 \%$ (11).

A study performed in Turkey by Ozden et al, on 305 patients, observed the effects of age on biochemical recurrence in patients who had undergone radical prostatectomy. The patients were divided into three groups based on age: $<60,60$ to 70 , and $>70$ years old. The rates of positive surgical margins, lymph node involvement, invasion of seminal vesicles, Gleason score and biochemical recurrence were not significantly different among the three age groups. The rate of biochemical recurrence after a follow-up period of 70 months was $20 \%$, which was similar to that found in the literature. Age $>70$ years was not a factor associated with biochemical recurrence (12).

\section{The natural history of biochemical recurrence}

According to clinical studies and to the literature, a biochemical recurrence after radical prostatectomy is not equal to clinical failure and metastases. Between $24 \%$ and $34 \%$ of men with PSA values $>0.2 \mathrm{ng} / \mathrm{ml}$ after surgery can develop metastatic disease in the postoperatory period (up to 15 years after surgery) (13). The patients who have greater risks of developing biochemical recurrence and metastatic disease are those with a short PSA doubling time, seminal vesicles invasion, a high Gleason score between 8 and 10 and biochemical recurrence under 3 years from the time of surgery (14).

If biochemical recurrence is detected following radical prostatectomy, the logical step to follow is to determine whether the biochemical recurrence is secondary to local recurrence or to metastatic disease, or in some cases to both, in order to determine the correct therapeutical protocol. In order to do so, bone scan, and abdomen and pelvic computed tomography must be performed. The probability of a positive bone scan in men with biochemical relapse after RP is $<5 \%$ if the PSA level is under $7 \mathrm{ng} / \mathrm{ml}(15,16)$.

\section{Therapeutical options}

There are several therapeutical options that can be applied for patients with biochemical recurrence after radical prostatectomy. Radiotherapy can be used in men with positive margins after surgery, as well as in patients with pT3 disease who present a risk greater than $50 \%$ of biochemical failure after radical prostatectomy (17). A study, conducted in 2011 on 1,815 patients with high-risk and locally advanced prostate cancer (discovered during surgery or after histophatological examination), concluded that radiotherapy significantly improved the risk of biochemical progression-free survival at five and ten years compared with patients in whom surgery was the only treatment option (18). Patients who present PSA recurrence after radical prostatectomy should be managed using salvaged radiotherapy. More than half of these patients who undergo salvage radiotherapy before the PSA levels exceed $0.5 \mathrm{ng} / \mathrm{ml}$ can achieve undetectable PSA and thus significantly reducing the risk of disease progression over the following years.

A retrospective analysis conducted on 635 patients with biochemical recurrence following radical prostatectomy evaluated the role of salvage radiotherapy in terms of improving the prostate cancer specific survival. A total of 160 patients received only salvage radiotherapy, 68 received salvage radiotherapy and ADT, whereas 397 patients did not receive any form of treatment following biochemical recurrence. The authors reported that $\sim 18 \%$ of the 635 patients died because of prostate cancer progression, after a mean period of six years after biochemical recurrence was confirmed. The group of patients managed with salvage radiotherapy achieved a significantly higher prostate cancer survival rate compared with those without any form of treatment. The authors noted that associating ADT to salvage radiotherapy did not bring any further improvements in terms of cancer-related survival compared to salvage radiotherapy alone. Another important conclusion of this study was that the patients who underwent salvage radiotherapy before reaching the period of two years from the biochemical recurrence (the PSA doubling time being less than six months) presented superior outcomes in terms of cancer survival compared with those for whom salvage radiotherapy was initiated more than two years after biochemical recurrence. According to the literature, the dose of salvage radiation should be at least 66 Gy (19).

A systematic review in 2016 regarding the dose response of salvage radiotherapy following radical prostatectomy concluded that a dose of at least 70 Gy should be recommended when biochemical recurrence is encountered. The authors noted that for each Gy the recurrence-free survival following salvage radiotherapy increases with $2.6 \%$ and that each $0.1 \mathrm{ng} / \mathrm{ml}$ of PSA correlates with a decrease of the recurrence-free survival rate by $2.4 \%$ (20). In general, a total dose of 64-66 Gy is well tolerated, it has been estimated that $<5 \%$ of the patients who receive this dose present the risk of developing complications secondary to the radiation-induced toxicity. Dose escalation provides superior outcomes in terms of re-achieving undetectable PSA values and prostate cancer survival, but it also increases the risk of radiation toxicity.

A clinical trial in 2015, conducted on 344 patients with biochemical recurrence after radical prostatectomy, who had undergone salvage radiotherapy, evaluated the patients' quality of life and radiation-associated toxicity. The patients have received either $64 \mathrm{~Gy}$ or $70 \mathrm{~Gy}$. The percentage of radiation-induced toxicity was slightly higher in the group of patients who have received a total radiation dose of $70 \mathrm{~Gy}$, with up to $3-4 \%$ higher, without a major negative impact on patients' quality of life. The authors reported that they 
encountered more bothersome urinary tract symptoms in the radiation dose-escalated group of patients compared to those who received a total dose of 64 Gy (21).

Intensity-modulated radiotherapy associates a lower risk of complications compared to conformational 3D radiotherapy. A retrospective analysis evaluated these two previously mentioned radiotherapy techniques in terms of radiation-induced toxicity in patients who presented biochemical recurrence following radical prostatectomy. Approximately two thirds of the patients had received a total radiation dose of $>70 \mathrm{~Gy}$. The authors reported that intensity-modulated radiotherapy presented superior results in terms of grade 2 gastrointestinal toxicity, but the genito-urinary tract toxicity, post-radiotherapy erectile dysfunction and urinary incontinence did not differ much between the two radiotherapy techniques (22).

For patients at high risk of biochemical recurrence following radical prostatectomy (extraprostatic extension, positive surgical margins, invasion of the seminal vesicles) there is a debate in terms of recommending adjuvant radiotherapy or surveillance and salvage radiotherapy when the PSA level increases. This debate is based on the risks of radiation-induced toxicity and also on the risk of overtreatment with adjuvant radiotherapy. According to existing data, the use of adjuvant radiotherapy for patients at high risk of biochemical recurrence is low, being estimated at $\sim 10 \%$. This can be explained by the fear of overtreatment and radiation-induced complications, as well as on the fact that a considerable percentage of these patients may never develop biochemical recurrence. Nevertheless, the risk of biochemical recurrence for high risk patients ranges between $40 \%$ and $70 \%$. The European Association of Urology recommends active surveillance and delayed salvage radiotherapy for patients with favorable factors such as Gleason score $\leq 7$, pathological stage $\leq \mathrm{T} 3 \mathrm{a}$ (extracapsular extension without seminal vesicle involvement), time to biochemical recurrence greater than 3 years and a PSA doubling time of over twelve months. The patients should undergo salvage radiotherapy when the PSA values become detectable and it should be initiated as soon as possible, before the PSA reaches $0.5 \mathrm{ng} / \mathrm{ml}$ (23).

Tendulkar et al (24) reported the results of a retrospective study that included 2460 patients with detectable PSA following radical prostatectomy, for whom salvage radiotherapy was performed. The authors reported an overall 5-years freedom from biochemical recurrence of $56 \%$. It was noted that the pre-salvage radiotherapy PSA level significantly influenced the 5-year rates of freedom from biochemical failure: $71 \%$ for patients with a PSA between $0.01-0.2 \mathrm{ng} / \mathrm{ml}, 63 \%$ for those with a PSA between $0.21-0.5 \mathrm{ng} / \mathrm{ml}, 54 \%$ for a PSA between $0.51-1 \mathrm{ng} / \mathrm{ml}, 43 \%$ for a PSA between 1.01 and $2 \mathrm{ng} / \mathrm{ml}$ and $37 \%$ for those who had a pre-salvage radiotherapy PSA $\geq 2 \mathrm{ng} / \mathrm{ml}$. The authors indicated that the PSA value before salvage radiotherapy, the Gleason score, positive surgical margins, extraprostatic extension, seminal vesicle invasion and the use of ADT were associated with freedom from biochemical failure. The majority of these factors were also associated with distant metastases, with the exception of total radiation dose and extraprostatic extension, which did not seem to be correlated with distant metastases. The authors concluded that salvage radiotherapy should be initiated as soon as possible, from the time the PSA becomes detectable, because it improves the freedom from biochemical recurrence and distant metastases rates.

A study published in 2018 compared adjuvant radiotherapy with early salvage radiotherapy in 1,566 patients who underwent radical prostatectomy. A total of 371 patients underwent adjuvant radiotherapy (the PSA level being $\leq 0.1 \mathrm{ng} / \mathrm{ml}$ ) and in 1,195 cases salvage radiotherapy was performed (PSA ranging between $0.1-0.5 \mathrm{ng} / \mathrm{ml})$. The period of time that passed from the surgery until the radiotherapy was initiated differed between the two groups. In the adjuvant radiotherapy group patients it was 4.4 months, whereas those included in the salvage radiotherapy group it was 22.9 months. The authors compared the results obtained with these two approaches in 366 propensity matched pairs of patients. The results obtained after a 12-year follow-up showed that adjuvant radiotherapy compared to early salvage radiotherapy offered better results in terms of freedom from biochemical recurrence (69\% vs. 43\%), freedom from distant metastases (95\% vs. $85 \%$ ) and overall survival (91\% vs. 79\%) (25).

The benefits of associating ADT with salvage radiotherapy for the management of patients with biochemical recurrence following radical prostatectomy is debatable. Nevertheless, several studies have published encouraging results. In 2017, the results of the RTOG 9601 clinical trial were published. The authors evaluated the benefits of adding deprivation androgen therapy to salvage radiotherapy. The patients enrolled in this study were divided into two groups: one group receiving $150 \mathrm{mg}$ bicalutamide daily for a period of two years, and the second group of patients received placebo daily. The results obtained after a follow-up period of 12 years showed that bicalutamide improved the overall survival rate, as well as the metastatic disease rate and death related to prostate cancer. The rate of metastatic prostate cancer was $14.5 \%$, whereas in the placebo group it was significantly higher, at $23 \%$. The death related to prostate cancer rate in the bicalutamide group was $5.8 \%$, compared to $13.4 \%$ in the group of patients who received placebo (26).

The GETUG-AFU 16 clinical trial also supports the association of ADT and salvage radiotherapy. A total of 743 patients who underwentradical prostatectomy and afterwards presented increasing PSA levels were enrolled in this trial. The patients were divided as follows: 374 patients who received salvage radiotherapy alone (3D-conformal radiotherapy or intensity-modulated radiotherapy with a total radiation dose of $66 \mathrm{~Gy}$ ) and 369 patients who received salvage radiotherapy plus goserelin (subcutaneous injection in the first day of radiotherapy and three months later). After a follow-up period of five years, it was recorded that the group of patients who received salvage radiotherapy and short-term ADT with goserelin had better results regarding the PSA progression, as well as in terms of clinical progression. The freedom from biochemical progression rate in the group of patients who received only radiotherapy was $62 \%$, whereas in the group of patients who received short-term goserelin and salvage radiotherapy this rate was significantly higher, at $80 \%$. The authors concluded that adding a short-term gonadotropin-releasing hormone analogue to salvage radiotherapy may be a better solution in the management of patients who present increasing PSA after radical prostatectomy compared to salvage radiotherapy alone (27). 
ADT is a salvage therapy after radical prostatectomy with biochemical recurrence, although data supporting its use is generally obtained from retrospective studies (28). Not all patients with biochemical recurrence can benefit from ADT, the best effects being in patients with high-risk with long life expectancy, also proving useful in those who refuse radiotherapy. After multiple studies searching for the optimal timing regarding the start of ADT early in the detection of biochemical recurrence versus late ( $>2$ years), it turned out that there is no difference between them (29).

The use of brachytherapy in case of biochemical recurrence after prostatectomy and salvage radiotherapy has limited indications and poor results, as the total dose that can be used is low. There are some selected cases with good results regarding high doses of brachytherapy within an acceptable toxicity range (23).

\section{Discussion}

The management of biochemical recurrence after radical prostatectomy is complicated, due to the numerous variables that must be taken into consideration. A study performed by Loeb et al (30) revealed that patients who develop biochemical recurrence more than five years after radical prostatectomy are less likely to present local or remote metastasis compared to those who develop biochemical recurrence in less than five years (31). Several studies have shown that there is no direct link between the time of appearance of biochemical recurrence and the risk of systemic progression or cancer-specific mortality in patients with low-risk prostate cancer $(32,33)$. However, in high-risk patients, the early biochemical recurrence seems to increase the risk of mortality, this being the result of disease progression and metastases. It is known that high PSA values before surgery, the presence of positive surgical margins, pathological stage and other factors are predictors of biochemical recurrence (34-39). It has been demonstrated that in patients with positive surgical margins, the tumor grade at the site of the positive margin has prognostic value and that the Gleason score of the radical prostatectomy specimen is associated with PSA velocity (40).

Prostate cancer is a disease that generally affects men, aged $>60$ years, and there is an estimated increasing trend in its incidence in further years. How age affects the development of prostate cancer is yet to be known, but androgen hormones are known factors in its pathogenesis. Age can also facilitate both carcinogenesis and the evolution and progression of cancer cells by producing various inflammatory mediators, such as interleukin-6, interleukin-10, and tumor necrosis factor (41).

\section{Conclusions}

Radical prostatectomy is the definitive treatment option for clinically localized prostate cancer. It is known that positive surgical margins, the presence of invaded lymph nodes, a high value of the PSA and the Gleason score are risk factors for the appearance of biochemical recurrence and prostate cancer mortality. There are many definitions of biochemical recurrence after radical prostatectomy, however, the PSA value $\geq 0.2 \mathrm{ng} / \mathrm{dl}$ is the most widely used. There are several salvage treatment options in patients who develop biochemical recurrence, such as radiotherapy and ADT, with good results.

\section{Acknowledgements}

Not applicable.

\section{Funding}

No funding was received.

\section{Availability of data and materials}

Not applicable.

\section{Authors' contributions}

OGB, DLDM, TC and RDM collected, analyzed and interpreted the patient data regarding the biochemical recurrrence after radical prostatectomy. CCD, AMAS, FIR and SGB had substantial contribution to the conception of the study and interpretation of data; also, they drafted the manuscript and were major contributors in writing the manuscript. All authors read and approved the final manuscript.

\section{Ethics approval and consent to participate}

Not applicable.

\section{Patient consent for publication}

Not applicable.

\section{Competing interests}

The authors declare that they have no competing interests.

\section{References}

1. Bell KJ, Del Mar C, Wright G, Dickinson J and Glasziou P: Prevalence of incidental prostate cancer: A systematic review of autopsy studies. Int J Cancer 137: 1749-1757, 2015.

2. Lupu M, Caruntu A, Caruntu C, Papagheorghe LML, Ilie MA, Voiculescu V, Boda D, Constantin C, Tanase C, Sifaki M, et al: Neuroendocrine factors: The missing link in non melanoma skin cancer (Review). Oncol Rep 38: 1327-1340, 2017.

3. Neagu M, Caruntu C, Constantin C, Boda D, Zurac S, Spandidos DA and Tsatsakis AM: Chemically induced skin carcinogenesis: Updates in experimental models (Review). Oncol Rep 35: 2516-2528, 2016.

4. Boda D: Cellomics as integrative omics for cancer. Curr Proteomics 10: 237-245, 2013.

5. Neagu M, Constantin C, Tanase C and Boda D: Patented biomarker panels in early detection of cancer. Recent Pat Biomark 1: 10-24, 2011.

6. Boda D, Docea AO, Calina D, Ilie MA, Caruntu C, Zurac S, Neagu M, Constantin C, Branisteanu DE, Voiculescu V, et al: Human papilloma virus: Apprehending the link with carcinogenesis and unveiling new research avenues (Review). Int J Oncol 52: 637-655, 2018.

7. Solomon I, Voiculescu VM, Caruntu C, Lupu M, Popa A, Ilie MA, Albulescu R, Caruntu A, Tanase C, Constantin C, et al: Neuroendocrine factors and head and neck squamous cell carcinoma: An affair to remember. Dis Markers 2018: 9787831, 2018. 
8. Lupu M, Caruntu A, Caruntu C, Boda D, Moraru L, Voiculescu V and Bastian A: Non-invasive imaging of actinic cheilitis and squamous cell carcinoma of the lip. Mol Clin Oncol 8: 640-646, 2018.

9. Voiculescu VM, Caruntu C, Solomon I, Lupu M, Ilie MA, Boda D, Constantin C and Neagu M: Squamous cell carcinoma: Biomarkers and potential therapeutic targets. Human Skin Cancers-Pathways, Mechanisms, Targets and Treatments. Blumenberg M: IntechOpen; London: pp135-159, 2018.

10. Rosenbaum E, Partin A and Eisenberger MA: Biochemical relapse after primary treatment for prostate cancer: Studies on natural history and therapeutic considerations. J Natl Compr Canc Netw 2: 249-256, 2004.

11. Beauval J-B, Roumiguié M, Filleron T, Benoit T, de la Taille A, Malavaud B, Salomon L, Soulié M and Ploussard G: Biochemical recurrence-free survival and pathological outcomes after radical prostatectomy for high-risk prostate cancer. BMC Urol 16: 26, 2016

12. Ozden C, Aktas BK, Bulut S, Erbay G, Tagci S, Gokkaya CS, Baykam MM and Memis A: Effect of age on biochemical recurrence after radical prostatectomy. Kaohsiung J Med Sci 33: 91-95, 2017.

13. Pound CR, Partin AW, Eisenberger MA, Chan DW, Pearson JD and Walsh PC: Natural history of progression after PSA elevation following radical prostatectomy. JAMA 281: 1591-1597, 1999.

14. Boorjian SA, Thompson RH, Tollefson MK, Rangel LJ Bergstralh EJ, Blute ML and Karnes RJ: Long-term risk of clinical progression after biochemical recurrence following radical prostatectomy: The impact of time from surgery to recurrence. Eur Urol 59: 893-899, 2011.

15. Gomez P, Manoharan M, Kim SS and Soloway MS: Radionuclide bone scintigraphy in patients with biochemical recurrence after radical prostatectomy: When is it indicated? BJU Int 94: 299-302, 2004.

16. Beresford MJ, Gillatt D, Benson RJ and Ajithkumar T: A systematic review of the role of imaging before salvage radiotherapy for post-prostatectomy biochemical recurrence. Clin Oncol (R Coll Radiol) 22: 46-55, 2010.

17. Karakiewicz PI, Eastham JA, Graefen M, Cagiannos I, Stricker PD, Klein E, Cangiano T, Schröder FH, Scardino PT and Kattan MW: Prognostic impact of positive surgical margins in surgically treated prostate cancer: Multi-institutional assessment of 5831 patients. Urology 66: 1245-1250, 2005.

18. Daly T, Hickey BE,Lehman M,Francis DP and See AM: Adjuvant radiotherapy following radical prostatectomy for prostate cancer. Cochrane Database Syst Rev 12: CD007234, 2011.

19. Trock BJ, Han M, Freedland SJ, Humphreys EB, DeWeese TL, Partin AW and Walsh PC: Prostate cancer-specific survival following salvage radiotherapy vs observation in men with biochemical recurrence after radical prostatectomy. JAMA 299: 2760-2769, 2008.

20. King CR: The dose-response of salvage radiotherapy following radical prostatectomy: A systematic review and meta-analysis. Radiother Oncol 121: 199-203, 2016.

21. Ghadjar P, Hayoz S, Bernhard J, Zwahlen DR, Hölscher T, Gut P, Guckenberger M, Hildebrandt G, Müller AC, Plasswilm L, et al: Acute toxicity and quality of life after dose-intensified salvage radiation therapy for biochemically recurrent prostate cancer after prostatectomy: First results of the randomized trial SAKK 09/10. J Clin Oncol 33: 4158-4166, 2015.

22. Goenka A, Magsanoc JM, Pei X, Schechter M, Kollmeier M, Cox B, Scardino PT, Eastham JA and Zelefsky MJ: Improved toxicity profile following high-dose postprostatectomy salvage radiation therapy with intensity-modulated radiation therapy. Eur Urol 60: 1142-1148, 2011.

23. European Association of Urology: Guidelines on Prostate Cancer 2018. Chapter 625. https://uroweb.org/guideline/prostate-cancer/\#6. Accessed February 13, 2019

24. Tendulkar RD, Agrawal S, Gao T, Efstathiou JA, Pisansky TM, Michalski JM, Koontz BF, Hamstra DA, Feng FY, Liauw SL, et al: Contemporary update of a multi-institutional predictive nomogram for salvage radiotherapy after radical prostatectomy. J Clin Oncol 34: 3648-3654, 2016.
25. Hwang WL, Tendulkar RD, Niemierko A, Agrawal S, Stephans KL, Spratt DE, Hearn JW, Koontz BF, Lee WR, Michalski JM, et al: Comparison between adjuvant and early-salvage postprostatectomy radiotherapy for prostate cancer with adverse pathological features. JAMA Oncol 4: e175230, 2018.

26. Shipley WU, Seiferheld W, Lukka HR, Major PP, Heney NM, Grignon DJ, Sartor O, Patel MP, Bahary JP, Zietman AL, et al; NRG Oncology RTOG: Radiation with or without antiandrogen therapy in recurrent prostate cancer. N Engl J Med 376: 417-428, 2017.

27. Carrie C, Hasbini A, de Laroche G, Richaud P, Guerif S, Latorzeff I, Supiot S, Bosset M, Lagrange JL, Beckendorf V, et al: Salvage radiotherapy with or without short-term hormone therapy for rising prostate-specific antigen concentration after radical prostatectomy (GETUG-AFU 16): A randomised, multicentre, open-label phase 3 trial. Lancet Oncol 17: 747-756, 2016.

28. Mottet N, Bellmunt J, Bolla M, Briers E, Cumberbatch MG, De Santis M, Fossati N, Gross T, Henry AM, Joniau S, et al: EAU-ESTRO-SIOG guidelines on prostate cancer. Part 1: Screening, diagnosis, and local treatment with curative intent. Eur Urol 71: 618-629, 2017.

29. Garcia-Albeniz X, Chan JM, Paciorek A,Logan RW, Kenfield SA, Cooperberg MR, Carroll PR and Hernán MA: Immediate versus deferred initiation of androgen deprivation therapy in prostate cancer patients with PSA-only relapse. An observational follow-up study. Eur J Cancer 51: 817-824, 2015.

30. Loeb S, Feng Z, Ross A, Trock BJ, Humphreys EB and Walsh PC: Can we stop prostate specific antigen testing 10 years after radical prostatectomy? J Urol 186: 500-505, 2011.

31. Solovastru LG, Vata D, Statescu L, Constantin MM and Andrese E: Skin cancer between myth and reality, yet ethically constrained. Rev Rom Bioet 12: 47-52, 2014.

32. Sinescu I, Geavlete P, Multescu R, Gangu C, Miclea F, Coman I, Ioiart I, Ambert V, Constantin T, Petrut B and Feciche B: Long-term efficacy of Serenoa repens treatment in patients with mild and moderate symptomatic benign prostatic hyperplasia. Urol Int 86: 284-289, 2011.

33. Constantin TV, Madan VL, Constantin MM, Morariu SH and Braticevici B: The role of prostate-specific antigen in prostate cancer screening. Rev Rom Med Lab 22: 275-281, 2014 (In Romanian).

34. Spinu D, Bratu O, Marcu D, Mischianu D, Huica R, Surcel M, Munteanu A, Socea B, Bodean O and Ursaciuc C: The use of ELISA and PCR in identifying correlations between viral infections and benign prostatic hypertrophy. Rev Chim Buchar 69: 645-649, 2018

35. Popescu R, Bratu O, Spinu D, Marcu D, Farcas C, Dinu M and Mischianu D: Neuroendocrine differentiation in prostate cancer - a review. Rom J Mil Med 118: 16-19, 2015.

36. Marcu D, Spinu D, Mischianu D, Socea B, Oprea I and Bratu O: Oncological follow-up after radical prostatectomy. Rom J Mil Med 120: 39-42, 2017.

37. Socea LI, Visan DC, Barbuceanu SF, Apostol TV, Bratu OG and Socea B: The antioxidant activity of some acylhydrazones with dibenzo[a,d][7]annulene moiety. Rev Chim Buchar 69: 795-797, 2018.

38. Radulescu A, Madan V, Aungurenci A, Bratu O, Farcas C, Dinu $M$ and Mischianu D: Antibiotic resistant urinary tract infections in a urology ward. Rom J Mil Med 118: 20-22, 2015.

39. Spinu D, Bratu O, Popescu R, Marcu D, Radulescu A and Mischianu D: Clostridium difficile - an emerging plague. Rom J Mil Med 118: 12-15, 2015.

40. Ahove DA, Hoffman KE, Hu JC, Choueiri TK, D'Amico AV and Nguyen PL: Which patients with undetectable PSA levels 5 years after radical prostatectomy are still at risk of recurrence? - Implications for a risk-adapted follow-up strategy. Urology 76: 1201-1205, 2010

41. Vasto S, Carruba G, Lio D, Colonna-Romano G, Di Bona D, Candore $\mathrm{G}$ and Caruso $\mathrm{C}$ : Inflammation, ageing and cancer. Mech Ageing Dev 130: 40-45, 2009. 